\title{
A Wittgensteinian approach to discerning the meaning of works of art in the practice of critical and contextual studies in secondary art education
}

\author{
Contact address: School of Education and Lifelong Learning, University of \\ Exeter, Heavitree Road, Exeter, EXI 2LU, UK
}

Tel: 0 I 392 264873; Fax: 0 I 39226492

e-mail - L.Cunliffe@exeter.ac.uk

\begin{abstract}
This article advocates an approach to critical and contextual studies in art education based on four references to meaning found in Wittgenstein's philosophy of language: meaning as use, meaning as rule-following, meaning as custom, and meaning as physiognomy. Each one makes up a different point on a compass for directing the will when discerning meaning in works of art. The will-toknowledge is directed towards forming judgments related to ponderable evidence of the contextual aspects of art, as revealed through meaning as custom, rule following, and use, all of which are reported through the third person. The will-to-understanding is directed towards making sense of imponderable evidence based on the physiognomic meaning of internal relationships of works of art, which are processed through first person responses. The self-as-will discerns continuity and discontinuity between ponderable and imponderable evidence for different aspects of meaning, and collates this knowledge and understanding to make judgments about a work's overall, multi-dimensional meaning. In attempting to see a work aright transpersonal explanations for context are combined with the personal understanding of critical studies, thus condensing meaning in works of art in such a way that students know how to go on.
\end{abstract}

to be published in the Journal of Aesthetic Education Spring 2006 


\section{A Wittgensteinian approach to discerning the meaning of works of art in the practice of critical and contextual studies in secondary art education}

In order to get clear about aesthetic words you have to describe ways of living. 1

Language is a labyrinth of paths. You approach from one side and know your way about; you approach the same place from another side and no longer know your way about. ${ }^{2}$

\section{Introduction}

This paper explores a Wittgensteinian approach for dealing with the meaning of works of art in the practice of critical and contextual studies in art education. The article is aimed at developing a methodology for eleven to nineteen year olds, known in the UK as the secondary phase of education, but the approach could be generalised to other phases.

Henry Finch 3 interprets four references to meaning found in Ludwig Wittgenstein's philosophy of language as a quadrant that combines the horizontal axis of meaning as physiognomies (the experiential and visual) and meaning as constructions (concepts, uses, science, and mathematics), with a vertical axis of meaning as imperatives (rule following, obligations, and law) and meaning as custom (ceremonies, myths, and ritual). ${ }^{4}$ The quadrant represents Finch's understanding of Wittgenstein's views about how language serves a different but complementary role in the way human beings engage with meaning in the world and their place in it. 5 Such meanings are embedded in social practices, including first person responses to a physiognomy, although these start off as biologically primed reactions.

Michael Luntley argues that Wittgenstein's philosophy of language and the related remarks on perception should be understood as setting conditions for the possibilities of judgment in "seeing the world aright, in taking the right attitude to the world"6 rather than simply mapping the possibilities of meaning, as the former underscores the role of will ${ }^{7}$ in the way meaning is actively witnessed and ethically processed by an agent. Having the right view is still only a view, but for Wittgenstein this amounted to an immense ethical and philosophical project to see things accurately and in correct relationship to each other. Such perspectival stances result from an agent's capacity to selectively engage with meaning, with a more unitary understanding resulting from criss-crossing the same territory from different points of view. Wittgenstein's four references to meaning can be thought of as forming four different points on a compass that directs the "self-as-will engaged with that which is independent of will " 8 in a quest to see things aright. By extension, such an approach could be used in art education to enable students to develop the dispositions to see works of art aright.

Marcia Eaton describes the tension between epistemic and interpretative approaches to the meaning of works of art in this way: "In which direction should one go? In other words, how can judgments which seem so personal (relative, subjective, etc.) also play a role in interpersonal (absolute, objective, etc.) language games?"' Michael Podro gives a similar description of the apparent tension between a context bound analysis of works of art and their irreducible and autonomous qualities as like "constantly treading a tightrope". ${ }^{10}$ Ralph Smith highlights the difference "between having knowledge about art and personally experiencing its presence and power." I

Ben Tilghman ${ }^{12}$ advocates a Wittgensteinian way of going beyond these two-fold approaches for understanding and interpreting art by focusing on the role that ponderable and imponderable evidence play in achieving the right stance when attempting to condense the meaning of works of 
art. Following Wittgenstein, Tilghman argues that a judgment based on imponderable evidence can often be supported by ponderable evidence, a process that is always linked to the relative experience, knowledge and wisdom of the person making the judgment. Wittgenstein's four references to meaning could be thought as points on a compass for directing the will in fittingness when endeavouring to understand the role and relationship of ponderable and imponderable evidence in any attempt to see works of art aright. But before these ideas can be further developed, it will be necessary to describe current shortcomings in the practice of critical and contextual studies in secondary art education in the UK.

\section{The current practice of critical and contextual studies in secondary education in the UK}

A rigorous practice of critical and contextual studies has been very slow to emerge in secondary education in the UK, where the autonomy of the art object promoted by formalism, along with the tendency of art education to perpetuate a false dichotomy between sensory experience and discursive enquiry, and between procedural and declarative forms of knowledge, still prevails. This dualistic way of thinking has its roots in the wider romantic and modernist legacy of understanding art and the creative process as a solitary, often idiosyncratic activity, which replicates the broader tendency in modern thought of detaching individuals and works of art from their wider sociocultural surroundings and roots, so that making and perceptually exploring art are seen as an autonomous practice carried out by a hidden ego.

This modernist paradigm should have disappeared long ago given that superior accounts of what constitutes knowledgeability in art education have emerged in the last thirty years. However, the legacy of the modernist and formalist approach continues to dominate art education in the UK to the detriment of the contribution that critical and contextual studies could make to students' understanding of art and what constitutes a thinking human being. This state of affairs might explain why developing knowledge of art in context and refining the related knowledge-seeking strategies for making different types of judgments for discerning the meaning of works of art are the weakest aspect of the art curriculum at all phases of education in the UK. Harland et al's empirical research supports this comment, as it identifies the main gap in the general provision of secondary arts education, including visual art education, as: "The development of critical discrimination and aesthetic judgment-making, especially the capacity to locate these in their social, artistic and cultural contexts; the furthering of thinking skills, or more accurately, a meta-awareness of the intellectual dimensions to artistic processes." 13

A consequence of the lack of clarity about how John Dewey's ${ }^{14}$ original distinction between procedural and declarative knowledge, later discussed by Gilbert Ryle, ${ }^{15}$ has resulted in these two forms of knowledge being conflated in art education in the UK, so that evidence for procedural knowledge is constantlyconfused with evidence for declarative knowledge. To know how to paint portraits in the style of Rembrandt is not evidence for knowing that about Rembrandt's practice of portrait painting in the context of life in seventeenth century Holland.

Although procedural knowledge in art has been the subject of a substantial amount of research that goes back several centuries, which in the last hundred years has embraced child art and selfexpression related to the idea of regression or "primitive" sources in search of an authentic, aboriginal essence, the essentialist approach of the visual grammar first developed at the Bauhaus, later recycled as basic design exercises, ideas in developmental psychology and cognitive psychology, the ability of students of all ages to learn how to become knowledgeable in the way they make judgments about art's contextual and other meanings has been relatively neglected. 
In the USA Michael Parsons ${ }^{16}$ used a constructivist and developmental model to explore aesthetic understanding. In arriving at his developmental explanation for aesthetic education, Parsons neglected two important things: first, that real art works have meanings that require understanding non-present, contextual but ponderable evidence to inform aesthetic judgments; and second, making judgments about the physiognomic, imponderable meanings of works art requires the cultivation of the "self-as-will" attitude for directing perceptual and interpretive strategies that, like understanding how to make judgments about ponderable evidence, are acquired from the mediation processes of social and cultural reality. Parsons' use of prompts precluded these possibilities as he was interested in establishing what students already know about interpreting art as opposed to what they might be able to learn and go on to independently practise. In doing so, Parsons lacked the Wittgensteinian insight, found at the beginning of this article, about aesthetic words needing to be linked to forms of living. This omission has been a generic weakness of psychological approaches to discerning meaning in works of art in art education.

In the UK, Rod Taylor ${ }^{17}$ used a case study method to explore secondary students' experience of meaning in works of art. In doing so he identified the "illuminating experience" as the vital ingredient, an idea derived from David Hargreaves' research with aesthetic autobiographies that suggested adults' sustained involvement with gallery and museum exhibitions was the result of "conversive trauma". ${ }^{18}$ Hargreaves arrived at this explanation because he found little evidence that it could result from the practice of secondary art education of the early 1980s that excluded any form of discourse, making art literally a dumb subject.

Hargreaves' idea of conversive trauma emerged from interview data, but it could be argued that this description of the nature of encounters with the meaning of works of art was already embedded in the legacy of discourse from the romantic tradition that saw art as an irrational, sometimes cathartic, and highly individual experience. Gombrich describes this romantic preoccupation with the ineffable in art as: “... the feeling that it is more than a sign, because it vouchsafes us a glimpse into vistas of meaning beyond the reach of convention and logic". 19 The psychological roots of this ineffable experience is explained by Gombrich in relationship to that aspect of cognition which involves the multiple or parallel processing of information, in contrast to the step-by-step linear processing of information and its related closures. With multiple processing closure is more elusive, hence the association of this form of perceptual engagement of art with the ineffable.

David Best 20 is suspicious of thinking of art as ineffable because it fails to account for the importance that knowledge and judgment play in understanding the meaning of works of art. Mihaly Csikszentmihayi and Rick Robinson's empirical research into museum curators' engagement with the meaning of works of art supports Best's criticism. Csikszentmihayi's and Robinson's findings show that the ineffable experience of art, although of crucial importance for stimulating curators' reactions, was quickly supplemented with knowledge of its contextual meanings, which, in turn, fed back into the perceptual exploration of the work to allow further, meaningful judgments to be formed, as this quote reveals. "Our studies show that while art historical knowledge may not increase the delight first experienced in encountering the object, it does provide layers of meaning that increase the challenge for the viewers and hence may make the experience more complex and enduring." 21

Csikszentmihayi and Robinson's research findings concerning the multi-dimensional way experts enter into the meaning of works of art could be seen as a paradigm for structuring critical and 
contextual studies for relative novices like secondary school students, as it exemplifies what novices need to do to learn how to operate more like experts.

\section{The role of ponderable and imponderable evidence in discerning the meaning of works of art}

Wittgenstein's four references to meaning referred to earlier can be thought of as operating as either text or face analogues, a contrast Wittgenstein makes between "seeing-as" or "aspect seeing" and "seeing"22. Wittgenstein contested the view that all perception and understanding is indirect like a text analogue, which presents a challenge to those who think of works of art as operating only in that way. Wittgenstein avoided conflating seeing with seeing-as through his reflections on grammar. We rarely describe what we see in terms of something else, unless, that is, the perceptual experience is very ambiguous. ${ }^{23}$ A person does not say: 'I see that fruit on the table as an apple and a pear.' Wittgenstein distinguished perceptual and conceptual aspects of perception like this: "I should like to say: there are aspects which are mainly determined by thoughts and associations, and others which are "purely optical." $24 \mathrm{He}$ maintained that phenomena are not the same as signs, and, by analogy, that not all works of art need be thought of as text analogues. This is not to advocate a bipartite approach that, on the one hand, deals with the meaning of phenomena and, on the other, the meaning of signs, but to recognise mutuality between experiential and conceptual thinking when understanding anything, including the variables of ponderable and imponderable evidence when making judgments about art.

A text analogue approach condenses meaning in relationship to ponderable, epistemic forms of evidence for works of art as embedded in their sociocultural context to embrace meaning as use, custom, and rule following. Such meanings have a text analogue character because they are usually non-present when viewing a work, requiring cultural and historical sources of knowledge to discern their dispersed intentionality, just as a text can only be read indirectly through acquiring the appropriate reading conventions. In this respect, Wittgenstein's notion of seeing-as or aspect seeing is not only subject to the will, as when selectively perceiving the duck-rabbit alternating image, ${ }^{25}$ but also subject to further conceptual explanations. "Sometimes the conceptual is dominant in an aspect. That is to say: sometimes the experience of an aspect can be expressed only through conceptual explanation. ${ }^{26}$ Seeing that man who carries a large sword and a book in Durer's painting as St. Paul is an example of such a conceptual aspect.

In contrast, a face analogue approach to works of art condenses meaning in relationship to imponderable evidence, just as a face can be explored for meaning and character without prior knowledge of the person's biography or life context. It was Wittgenstein's conviction that reactions to and judgments about faces and their character, although somewhat imponderable, were susceptible to fine-tuning through the right kind of experience and mediated learning.

Can one learn this knowledge? Yes; some can. Not, however, by taking a course in it, but through 'experience'. - Can someone else be a man's teacher in this? Certainly. From time to time he gives him the right tip. This is what 'learning' and 'teaching' are like here. - What one acquires here is not a technique; one learns correct judgments. There are also rules, but they do not form a system, and only experienced people can apply them right. Unlike calculating rules. ${ }^{27}$

Wittgenstein's description of forming judgments about what faces reveal about human character can be extended, by analogy, to encounters with works of art, as these also engage a similar cycle of perceptual reactions and linguistic descriptions in an attempt to ponder their physiognomy, to sense their expressive and other properties, their internal coherence or lack of it, in order to 
establish and articulate a more informed point of view. Such linguistic probes could be purely reflexive in attempting to see the work aright. Kjell Johannessen contrasts Wittgenstein's earlier tendency to assert that aesthetic value was beyond verbal analysis and description with his later work, which does allow for linguistic description of aesthetic reactions. Johannessen summarises Wittgenstein's later viewpoint like this: "We should regard aesthetic enquiries as a central element of aesthetic discourse; that we should regard the artwork as prototypical of physiognomic meaning, involving an intransitive form of understanding, whereby the crucial factor is the internal relationship between the expression and the content." 28 Johannessen highlights the importance of the intransitive form of understanding because he wants only the phenomenon of the work to be given attention.

Gary Hagberg29 broadens the Wittgensteinian "analogical bridge" between works of art and physiognomic meaning by comparing Charles Taylor's ${ }^{30}$ description of the capacities and attributes of persons with those of art works to show that both the concept of personhood and the concept of an art work engage with moral and legal discourse; a person's moral status and rights are analogous to art works having a certain artistic integrity that can be misrepresented, violated or debased; a person's sense of self can be analogous with a work of art having a certain internal coherence; a person's capacity to hold values can be analogous with a work of art projecting values; the human capacity to make choices can be analogous with a work being the depository of artistic choices; the human capacity to formulate a life-plan can be analogous with works of art revealing directedness in artistic development, and so on. These extended analogies between persons and works of art would engage transitive forms of understanding.

\section{The will-to-knowledge and the role of ponderable evidence: text in context}

The will-to-knowledge is directed at ponderable evidence and seeks explanations for works in terms of their use, custom, and rule following by understanding the conventions and practices of art as causally linked to their background context. It uses third person forms of reporting to generate transpersonal judgments, an approach in which: "Students move out to engage with the forms of the culture, while the forms of the culture, in turn, come to occupy their imagination." 31 Karl Popper's ${ }^{32}$ idea of the "logic of situations" strengthens such a knowledge-seeking approach, as it requires explanations of cultural and historical events that allow for the possibility of reconstructing a feasible course of action a person or group might have taken in a given cultural context when attempting to solve a problem or realise an aim.

Ernst Gombrich has used this method as a way of refining judgments for demarcating plausible explanations from more speculative interpretations of artistic styles and meaning of works of art. An example is the way Gombrich contests Freud's interpretation of Leonardo's painting The Virgin and Child with St. Anne which, he claims, is highly speculative and implausible, because it takes little or no account of the context in which Leonardo painted the work. Freud's psychoanalytic speculations were based around Leonardo's illegitimate birth that, in effect, resulted in him having the equivalent of two mothers, which might be the reason for the presence and relationship of two mothers in the painting. Gombrich's alternative explanation for the composition is derived from his knowledge of the contextual conventions for representing St. Anne. In doing this commission, Leonardo would have no choice about Mary being placed in St. Anne's lap, as this was already established by the genre. It is also a known fact that the choice of painting St. Anne was due to her being the patron saint of Florence, the city that commissioned Leonardo to paint the work. Although interesting, Freud's physiognomic interpretation is over-reliant on imponderable evidence that links Leonardo's upbringing to the content of the painting, which is somewhat at odds with judgments arrived at by weighing the wider, dispersed evidence based on the logic of the situation in which the work was made. 
Freud falls for what Gombrich describes as the "physiognomic fallacy"33: that we can infer all the meanings in a work of art from its less ponderable forms. David Summers explains Gombrich's position like this: "The gist of these arguments is that the meanings we simply see in works of art, although not without their own value, are not historical, and therefore not explanatory. In order to gain such understanding we must actually do history." ${ }^{34}$ Doing history in this case would involve exercising the will-to-knowledge directed at ponderable evidence related to meaning as use, meaning as custom, and meaning as rule following, which will now be discussed in more detail.

\section{Meaning as use}

Art from different cultures has been used for different purposes, with the vast majority having a ritual, sacred function. Michael Baxandall gives an account of the way Renaissance art was used in the fifteenth century Italy.

Most fifteenth century pictures are religious pictures. This is self-evident, in one sense, but 'religious pictures' refers to more than just a range of subject matter; it means that the pictures existed to meet institutional ends, to help with specific intellectual and spiritual activities. It also means that the pictures came within the jurisdiction of a mature ecclesiastical theory about images. 35

By contrast, western art from the early nineteenth century onwards has been increasingly used to subvert expectations, ${ }^{36}$ culminating in current theories like those of Arthur Danto 37 who argues that contemporary art's main use is to debate what constitutes art, a use alien to most of the art that has ever been made.

\section{Meaning as custom}

Customs are culturally specific ways of acting, to include business practices, ceremonies, rituals, the use of local materials, and the like. In the Renaissance, it was the custom for artists to work to commission. Contracts were drawn up that specified the subject matter, how the client would pay for the work, and when it should be completed. The contract described the quality of pigments and materials that were to be used. Renaissance artists' contracts were necessary because they worked to commission.

In the early twentieth century, Picasso was given a contract that allowed him to make art for the market, which was sold through Kahnweiler's dealership. His contract with Kahnweiler gave Picasso greater flexibility than that of his contemporaries in the size of paintings he could make, and also allowed him to retain his own work. ${ }^{38}$

It was not the custom for medieval artists to think of themselves as artists in the modern sense, but as skilled craftsmen or tradesmen regulated by a local guild who would have collaborated in workshop practice. Gothic cathedrals exemplify this form of art practice. Richard Anderson ${ }^{39}$ argues for similar customs in the role of artists and art in non-European cultures where conserving shared values and beliefs dominated artistic endeavour.

\section{Meaning as rule following}

Artistic procedures can be understood as resulting from a set of judgments based around meaning as rule following and its corollary of meaning as rule breaking. In Wittgenstein's lectures on 
aesthetics, a student recorded him making the following remarks about rules in music: "All the greatest composers wrote in accordance with them." 40 The notes go on to show Wittgenstein qualifying this remark after it had been contested. "You can say that every composer changed the rules, but the variation was very slight; not all the rules were changed. The music was still good by a great many of the old rules. -This though shouldn't come in here."4lGombrich describes this gradualist approach in which the variation in rules for art changed over time as the coral reef of style.

In the same lecture, Wittgenstein explores the idea of an artistically correct judgment by contrasting a tailor who knows about rules for making garments with one who has developed " $a$ feeling for the rules". ${ }^{42}$ Cyril Barrett ${ }^{43}$ sees this distinction as an indication that rules for regulating behaviour are worked out in practice before they are explicitly formulated for practice. Wittgenstein goes on to make the important point that knowing the rules inevitably leads to more refined judgment, which could be interpreted as a normative statement about the importance of rules for informing artistic and aesthetic practices.

The role and variation in rule following can only be grasped by gaining knowledge of how people of different times and cultures have used different procedures for making art. One example of rule following in art education in the UK is the importance given in the National Curriculum and public examinations of students show evidence of development of their work from preparatory studies to their final, artistic products. It is sometimes argued by art teachers that this form of rule following is unjustified because in many cultural practices of art there is no tradition of producing preparatory studies or working drawings. This objection can be contested, for even in cultures where there are no established practices of doing preparatory drawings, there is still a necessary reliance on the inherited artistic schemata of such traditions to guide or constrain choices for making art and the associated use of style and materials. Such schemata have an equivalent role to preparatory drawings in that they give background direction to a particular practice and the further possibilities for realising a finished artistic product.

Alois Riegl's book Stilfragen convincingly argued that ornament on buildings and artefacts resulted from schemata derived from tradition rather than improvised on the spot after technical and other difficulties had been overcome. In ancient Egypt artists worked within inherited schemas that changed little over time, thus ensuring a stable, visual tradition. In the medieval period, gothic churches and cathedrals were built from pattern books that circulated around Europe. During the Renaissance artists did precise working drawings so that patrons could anticipate how the commission would look when finished. Henry Moore exhaustively explored an idea in preparatory drawings. As a sculptor, Moore had to have a reasonably clear idea about how to proceed on the final piece as any unexpected changes at that stage could be costly in time and materials. Picasso's radical departure from the prevailing western style of representation was made possible by appropriating visual schemata from non-European art.

Meaning as rule following also explains artistic decisions in relationship to symbolic function. Ritualistic purposes for art prescribe specific conventions or rules to generate visual metaphors of value consonant with a consoling or mythic purpose for which the art has been made. In most historical cultures such practices were relatively stable because they represented the sacred views of the whole society, and to change the look of the art could undermine the shared beliefs of the community or tribe. By contrast, the avant-garde tradition championed art practices that stressed novelty and shocking the public, which begs the question as to whether this is a case of breaking a rule or more like a group of artists and their circle establishing and keeping a new rule? Charles Harrison et als ${ }^{44}$ claim that avant-garde artists in Paris at the beginning of the twentieth century were more like the latter, in that breaking an artistic code, a social convention, or frustrating an 
expectation, became a way of, paradoxically, following a rule. Artists of successive generations have been compliant with this inflationary form of rule following, making much current art practice, in the words of George Steiner, "nothing more and nothing less than a rhetorical tactic". 45

\section{The will-to-understanding and imponderable evidence: sensing meaning in the face of art}

\section{Meaning as physiognomy}

The will-to-understanding imponderable evidence is directed at seeing the internal relationships of the phenomena of works of art aright. This is achieved by attending to aesthetic reactions that are supported by further reasoning, a result of the art being actively witnessed for understanding rather than passively viewed, with the judgments representing a first person testimony to meaning as physiognomy.

Because the first person perspective is so embedded in the life world, Lynn Rudder Baker 46 thinks this beguiles us into neglecting its complexity. She highlights the role psychological verbs play in articulating what she describes as "I* thoughts", and uses the example of Timothy McVeigh reading a third person newspaper account of his forthcoming execution as "I*knowing". Baker ${ }^{47}$ thinks that this form of first person understanding is of a different order to third person knowledge, as it requires that extra, self-conscious element of making sense. One can know a lot about the way a work of art engages with contextual meaning as rule following, custom, and use, but none of these necessarily lead to the kind of critical and aesthetic awareness that results from the commitment of the self-as-will first person perspective in sensing meaning as physiognomy, an argument not unlike Ralph Smith's contrast between having knowledge about art and the role of will in personally experiencing its meaning. Smith maintained that the ability to experience such aesthetic percipience was the result of developing certain dispositions. This echoes Wittgenstein's description about how understanding people's faces and character results from cultivating similar dispositions.

In the UK Rod Taylor ${ }^{48}$ developed a method of form, content, process, mood to nurture dispositions for secondary art students to engage with works of art. Taylor provides case studies of subjects experiencing first person understanding in which the four categories are used to selectively explore a work for meaning as physiognomy, so that engaging with mood takes on a different aspect to that used for analysing process.

In the USA Margaret Johnson ${ }^{49}$ describes a method for developing dispositions based on Eugene Kaelin's phenomenological aesthetic theories that draw on the ability of human beings to have a first person perspective. The introductory stage involves "bracketing off" the work from other aspects of meaning in order to erase students' prejudiced responses, making it possible for them to ponder the work in question through ten stages of sensory exploration in which students are prompted to make a series of reflective judgments about the work's qualities.

Leslie Cunliffe ${ }^{50}$ has developed semantic differentials for nurturing students' disposition to sustain perceptual exploration of a work of art that uses antonyms separated on a seven-point scale. The antonyms can be loaded to generate a variety of judgments, to include any one of Taylor's four categories of mood, form, process, and content. Students circle the point on the scale equivalent to the given antonyms. If they think the work has an "angry" mood, they register this by ringing a I, "gentle", they ring a 7, somewhere in between, they ring a number equivalent to where the perceived value lies. The semantic differential provides a degree of plasticity necessary for making 
judgments about imponderable evidence of works of art. Students use a first person form of reporting to complete the following sentence: I think I will give this work of art a [number $X$ ] on the angry/gentle scale because

Taylor's, Johnson's, and Cunliffe's interventions to support the development of dispositions for making aesthetic judgments about the physiognomy of art works are attempts to give what Wittgenstein describes as the '....right tip. - This is what learning and teaching are like here.' The same rigour is required for "I*" understanding of imponderable evidence as is required for representing ponderable evidence using the third person.

\section{Conclusion}

This article advocates an approach for the teaching critical and contextual studies in secondary art education based on Wittgenstein's philosophy of language in relationship to meaning as use, custom, rule following, and physiognomy. The references to meaning form four metaphorical points on a compass for directing the will for making judgments about art. The metaphor is apt because a compass makes it possible for a relative novice to get around territory that otherwise would present problems for them to find their way around. The will-to-knowledge is directed at developing explanations based on ponderable evidence of the context in which the art was made, which are expressed in the third person. The will-to-understanding is directed towards making sense of imponderable evidence, in which "I*" witness, first person forms of reporting are emphasised. These various points of view combine transpersonal explanations for contextual studies with personal understandings for critical studies. In this process of coming into understanding, the will is always directed and structured by Wittgenstein's idea of language operating as meaning as use, meaning as rule following, meaning as custom, and meaning as physiognomy, all of which build an understanding of art's complexity and the role that grammar plays in any intentional act when attempting to see it aright.

\section{7 words - should be 5,000}




\section{References}

I. Ludwig Wittgenstein, Lectures and Conversations on Aesthetics, Psychology and Religious Belief, ed. Cyril Barrett (Oxford: Blackwell, 1970), II \#35

2. Ludwig Wittgenstein, Philosophical Investigations, eds. Elizabeth G M Anscombe \& Rush Rhees, trans. G.E.M. Anscombe, rev. 3rd ed., (Oxford: Blackwell, 200I), 69 \#203

3. Henry L Finch, Wittgenstein (Shaftesbury: Element Books, 1995), 57

4. Ludwig Wittgenstein, Philosophical Investigations, 18 \#43; 42-43 \#125; 10 \#23, 122 \#536, p. 186

5. See Nigel Pleasants, "The Post-Positivist Dispute in Social Studies of Science and its Bearing on Social Theory," in the Journal of Theory, Culture and Society, 1997, 14:3, I43-156; John Shotter, "Wittgenstein in Practice: from 'The Way of Theory' to a 'Social Poetics'," in Problems of Theoretical Psychology, ed. Charles Tolman, Frances Cherry, Rene Van Hezewijk, and lan Lugek (York, Ontario: Captus Press, 1996); John Shotter, Seeing Historically: Goethe and Vygotsky's "Enabling Theory-Method, on website:_http://pubpages.unh.edu/ ids/CYNTHIA C\&P.htm, 1998; Newton Garver, "Naturalism and Transcendality: the Case of Form of Life", in Wittgenstein and Contemporary Philosophy, ed. Souren Teghrarian (Bristol: Thoemmes Press, 1994), 41-69

6. Michael Luntley, Wittgenstein, Meaning and Judgment, (Oxford: Blackwell, 2003), 18

7. Richard Eldridge, Leading a Human Life: Wittgenstein, Intentionality, and Romanticism, Chicago: University of Chicago Press, 1997)

8 Michael Luntley, op. cit, I52

9. Marcia Muelder Eaton, "The Intrinsic Non-Supervenient Nature of Aesthetic Properties", The Journal of Aesthetics and Art Criticism, 1994, 52:4, 283

10. Michael Podro, The Critical Historians of Art, (London: Yale university Press)

II. Ralph Smith, Excellence II: The Continuing Quest in Art Education (Reston, Va.: The National Art Education Association, 1995), 28.

12. Ben Tilghman, Wittgenstein, Ethics and Aesthetics: the View from Eternity, (Albany: State University of New York Press, 1991), 21-42

13. John Harland et al. (2000) Arts Education in Secondary Schools: Effects and Effectiveness (Slough, NFER), 566

14. John Dewey, Human Nature and Conduct: an Introduction to Social Psychology, (London: Allen \& Unwin, 1922), 178

15. Gilbert Ryle, The Concept of Mind, (London: Hutchinson, 1949)

16. Michael J Parsons, How We Understand Art: a Cognitive-Developmental Account of Aesthetic Experience, (Cambridge, Cambridge University Press, 1987)

17. Rod Taylor, Educating for Art, (Harlow, Longman, 1986)

18. David Hargreaves, "The Teaching of Art and the Art of Teaching: towards an Alternative View of Aesthetic Learning," in Curriculum Practice: some Sociological Case Studies, eds. Martyn Hammersley \& Andy Hargreaves (London: Falmer, 1983), 127-I47

19. Ernst H Gombrich, "The Use of Art for the Study of Symbols," in The Essential Gombrich, ed. Richard Woodfield (London: Phaidon Press, 1996), 450-456

20. David Best, The Rationality of Feeling, (London: Falmer, 1992)

21. Mihaly Csikszentmihalyi \& Rick E Robinson, The Art of Seeing: an Interpretation of the Aesthetic Encounter (Los Angeles: Getty Museum \& Getty Education Institute for the Arts, 1990), 129

22. Ludwig Wittgenstein, Philosophical Investigations, 165-169e

23. Ray Monk, Ludwig Wittgenstein: the Duty of Genius, (Vintage Books: London, 1991), 489-5I9

24. Ludwig Wittgenstein, Remarks on the Philosophy of Psychology, Vol. I, eds. Elizabeth G M Anscombe \& Georg H von Wright, trans. G.E.M. Anscombe, (Oxford: Blackwell, 1980), \#970

25. Ludwig Wittgenstein, Philosophical Investigations, I82e 
26. Ludwig Wittgenstein, Last Writings on the Philosophy of Psychology, Vol.I, eds. Georg H. von Wright \& Heikki Nyman, trans. C. G. Luckhardt \& M.A.E. Aue, (Chicago: University of Chicago Press, 1980), 582

27. Ludwig Wittgenstein, Philosophical Investigations, 193e

28. Kjell S Johannessen, "Wittgenstein and the Aesthetic Domain," in Wittgenstein, Aesthetics and Philosophy, ed. Peter. B. Lewis, (Aldershot, Ashgate Press, 2004), 12

29. Gary L Hagberg, Art as Language: Wittgenstein, meaning, and Aesthetic Theory, (London, Cornell University Press, 2004), 180-185

30. Charles Taylor, "The Concept of a Person", in Human Agency and Language: Philosophical Papers, Vol. I(Cambridge: Cambridge University press), 97-II4

31. Peter Abbs, The Educational Imperative, (London: Falmer, 1994), 46

32. Karl R Popper, The Poverty of Historicism, (London: Routledge, 1957)

33. David Summers, "Form', Nineteenth Century Metaphysics, and the Problem of Art Historical Description," in The Art of Art History: a Critical Anthology, ed. Donald Preziosi (Oxford: Oxford University Press: 1998), 134

34. Ibid, 135

35. Michael Baxandall, Painting and Experience in Fifteenth Century Italy, (Oxford: Oxford University Press, 1972), 40

36. See Anthony Julius, Transgressions: the Offences of Art, (London: Thames \&Hudson, 2002); Leslie Cunliffe, "Connectivity for Showing and Saying Across Differences," in the International Journal of Art and Design Education, 2003, 22:3, 305-3I5

37. Arthur C Danto, The Transformation of the Commonplace, (Cambridge, Ma: Harvard University Press, 198I)

38. Charles Harrison, et al, Primitivism, Cubism, Abstraction - the Early Twentieth Century (London: Yale University Press, 1993) 176

39. Richard L Anderson, Calliope's Sisters: a Comparative Study of Philosophy of Art, (London: Prentice Hall, 1990)

40. Ludwig Wittgenstein, Lectures and Conversations on Aesthetics, Psychology and Religious Belief, op cit, $6 \# 16$

4l. Ibid, $6 \# 16$

42. Ibid, 5 \#I5

43. Cyril Barrett, "Changing the Rules in Art, " in Wittgenstein and Aesthetics, ed. Kjell S Johannessen (Bergen: University of Bergen, 1997), 4-5

44. Charles Harrison, op cit, 174- 178

45. George Steiner, Grammars of Creation, (London: Faber, 1989), 276

46. Lynne Rudder Baker, "Must Science Validate All Knowledge?" in The Nature and Limits of Human Understanding, ed. Anthony J. Sanford (T\&T Clark: London, 2003), 165-208

47. Ibid, 186

48. Rod Taylor, Visual Arts in Education, (London: Falmer, 1992)

49. Margaret $\mathrm{H}$ Johnson, "Phenomenological Method, Aesthetic Experience, and Aesthetic Education," in the Journal of Aesthetic Education, 1998, 32:I, 31-4I

50. Leslie Cunliffe, "Enhancing Novices' Abilities to Achieve Percipience of Works of Art," in the Journal of the Empirical Studies of the Arts, 1999, 17:2, 155-169 